\title{
The 25th Anniversary of Laser Vision Correction in the United States
}

This article was published in the following Dove Press journal:

Clinical Ophthalmology

\author{
Stephen N Joffe $\mathbb{B}^{1,2}$ \\ 'History of Medicine, Cedars-Sinai \\ Medical Center, Los Angeles, CA, USA; \\ ${ }^{2}$ Department of Surgery and Medicine, \\ University of Cincinnati Medical Center, \\ Cincinnati, $\mathrm{OH}$, USA
}

\begin{abstract}
Laser Vision Correction (LVC) is an elective, self-pay and safe surgical procedure to correct myopia and hyperopia. Since FDA approval 25 years ago, there have been a progression of technological improvements leading to better outcomes and LVC is now one of the safest surgical procedures. With a potential pool of 50 million patients, 6000 trained ophthalmic surgeons regularly treating in over 1000 centers of which $65 \%$ are physician owned. Treatments remain low from an earlier peak of 1.4 million to less than 800,000 over last 10 years. The factors preventing patients undergoing surgery have not changed and include the cost of $\$ 2000 \pm \$ 1000$ per eye and fear of laser surgery on their eyes. The latter is overcome by word of mouth referrals and positive social media messaging. In addition, press misinformation and lack of optometrists participating in co-management have not helped grow LVC procedures despite the positive results of the FDA's Patient Reported Outcomes with LASIK studies known as PROWL. The surgery is quick, and patients can be "in and out" in less than two hours with a rapid recovery, minimal postoperative restrictions and within 24 hours have 20/20 vision. Volume and price drives center and physician profitability with a scheduling capacity of two to four patients' treatments per hour. Laser vision correction and especially LASIK, remains the treatment of choice for myopic and hyperopic patients wanting to remove their dependency on glasses and contact lenses.
\end{abstract}

Keywords: LASIK, excimer, optical, contacts, glasses, Covid-19

\section{Introduction}

In the twenty-five years since the US Food and Drug Administration (FDA) approval for laser vision correction (LVC) to treat myopia and hyperopia with astigmatism there has been a progression of technological improvements from unilateral Photorefractive Keratectomy (PRK), to bilateral Laser-assisted in situ keratomileusis (LASIK) with wavefront or topographical guided treatments. ${ }^{1-10}$ The flap initially created by a mechanical microkeratome now uses a femtosecond laser. ${ }^{11-13}$

Excellent clinical results with minimal side effects leads to extremely satisfied patients.

We estimate over the last twenty-five years only 20-25 million eyes were treated with less than 800,000 eyes being treated each year for the last ten years. The penetration of potential patients for treatment remains low at $0.2 \%$ per annum. ${ }^{14}$

Word of mouth referrals and social media reviews have diminished the fear factor, but cost remains an issue. The laser vision correction and particularly LASIK remains the treatment of choice for myopic and hyperopic patients wanting to remove their dependency on glasses and contact lenses. ${ }^{6-10}$
Correspondence: Stephen N Joffe Joffe Foundation, 4400 Drake Road

Cincinnati, OH, USA

Tel + I 5 I3 27| 0670

$\mathrm{Fax}+15132718426$

Email stephen@sjoffe.com 
The manuscript is a personal perspective exploring the potential market size for refractive surgery, ophthalmologists trained and performing the procedure, location of lasers for treatment, pricing of treatment, economic impact on a surgeon's practice, clinical outcomes, and effect of Covid-19 and teleophthalmology in the USA but can also relate to the European market.

\section{Materials and Methods}

Literature searches were conducted in multiple databases including Medline, PubMed, Scopus, Cochrane, Google Search Engine and other internet and manual reviews of citations and related articles. Other sources included industry publications, paid subscriptions to research sources, interviewing ophthalmologists, optometrists, and management in the refractive industry, personnel at vision centers and a personal perspective with involvement in various capacities and in the laser vision correction industry.

In addition, SEC filings including industry quarter, annual financial reports from Companies affiliated with ophthalmology, optometry, medical devices, vision and refractive surgery have been reviewed.

The material presented includes the refractive market, ophthalmologists, procedures performed, pricing, clinical outcomes, and effect of Covid-19 pandemic in the USA.

\section{Results and Discussion \\ The Refractive Market}

It is estimated that $75 \%$ of adult Americans or over 230 million people have some vision problem requiring correction. Eyeglasses are worn by $50 \%$ of the population and up to $14 \%$ or 46 million individuals wear contact lenses. Some individuals wear contacts for social occasions and glasses at work.

Myopia (Nearsightedness) is the most common refractive disorder occurring in $28 \%$ of the USA population and an additional $15 \%$ are hyperopic with or without presbyopia. The cause of myopia is unknown, but incidence varies with age, gender, geography, race, genetic lines, education, early reading, time spent outdoors and computer activities. Myopia is found more frequently in younger white females with graduate education and higher socio-economic status. Up to $80 \%$ of Chinese children are myopic and references are made to an "epidemic" occurring.

The 45 million (14\%) myopic patients who wear contact lenses tend toward soft and disposable lenses. Myopia accounts for over $80 \%$ of LVC procedures. ${ }^{14}$
The second category for LVC is hyperopia (Farsightedness) which is found cumulatively in $15 \%$ of an older adult population. Nearly all patients undergoing LVC have astigmatism which is corrected simultaneously. Figure 1 shows the various categories of vision disorders and the percentage of patients with these issues as adapted from the MarketScope Report. ${ }^{14}$ (See Figure 1)

As shown in Figure 2, adapted from the MarketScope Report, glasses and contact lenses are the treatment of choice with a very low $(0.2 \%)$ penetration for LVC. ${ }^{15}$ (see Figure 2)

The vision correction market generated in professional service fees of over $\$ 5$ billion in 2016 and by 2019 it increased to $\$ 6.3$ billion mainly provided by independent eye care providers. Sale of contact lens is approximately $\$ 4$ Billion; eyeglass frames \$6 Billion and prescription lenses have sales of $\$ 9$ Billion per annum in USA.

The revenue from cataract surgery, which is the most common surgical procedure, is estimated at $\$ 11$ Billion with 3.7 million procedures performed in 2020 by 9000 ophthalmic surgeons in USA. ${ }^{16}$

This is in contrast to less than 800,000 laser refractive procedures being performed by approximately 3000 ophthalmic surgeons with an estimated revenue of $\$ 1.5$ Billion in 2020. ${ }^{15}$

Other ophthalmic surgical procedures include the use of retinal photocoagulation, vitrectomies and glaucoma treatments with lasers, filters, and shunts.

\section{VISION DISORDERS IN USA}

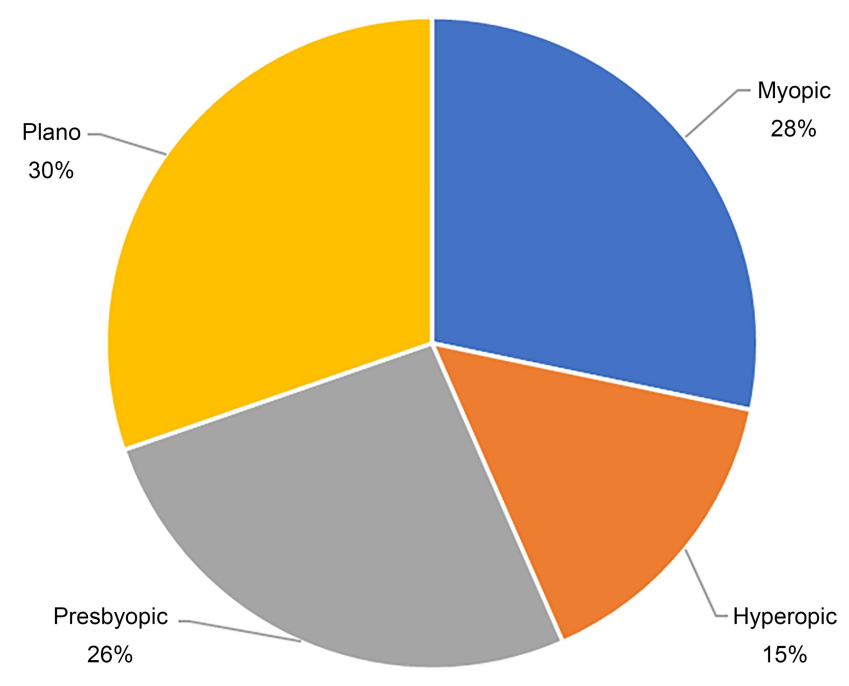

Figure I Vision disorders in USA. This figure demonstrates in a pie chart the percentage of patients with normal vision $(30 \%)$, myopic $(28 \%)$, hyperopic $(15 \%)$ and presbyopic (26\%). 


\section{METHOD OF VISION CORRECTION IN USA}

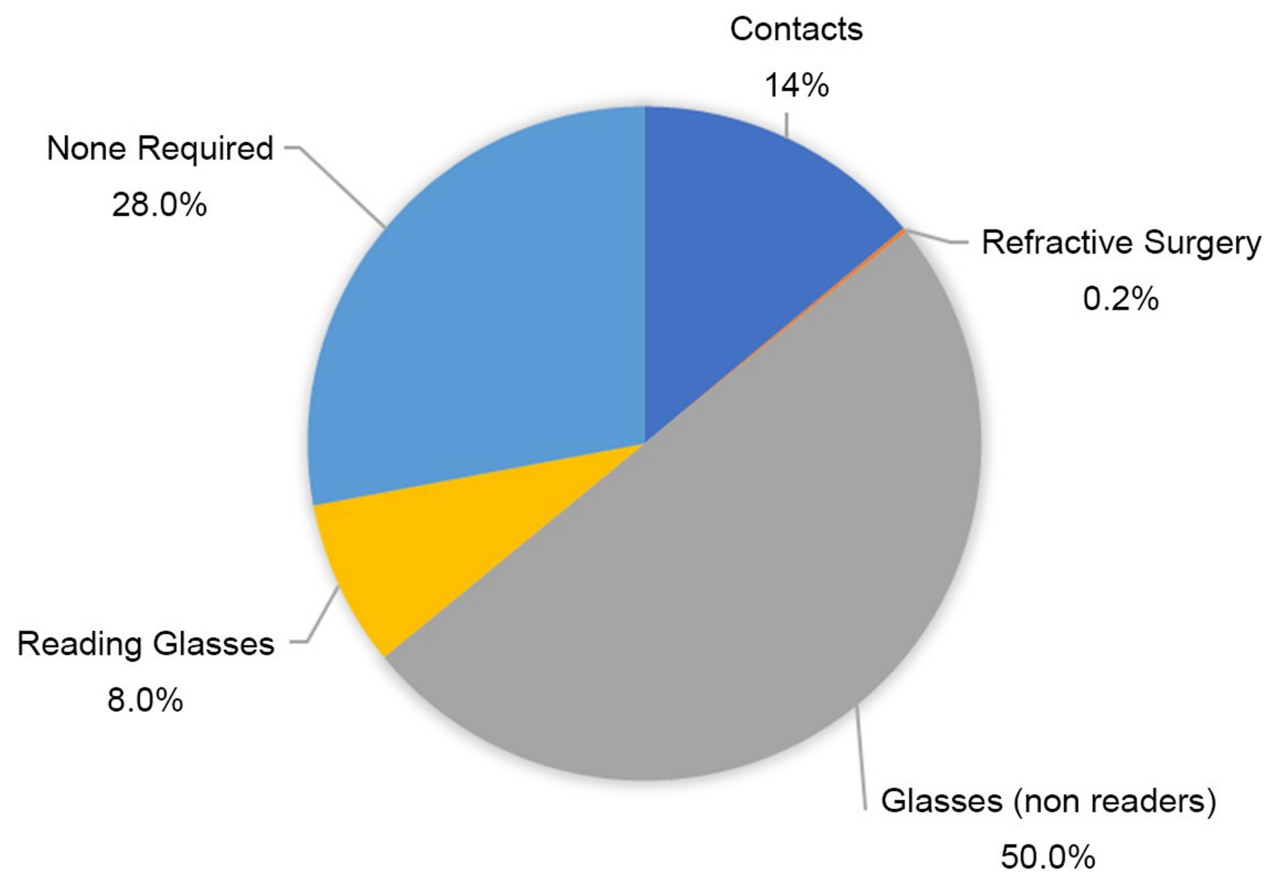

Figure 2 Method of vision correction in USA. This figure demonstrates in a pie chart how vision is corrected on adults in the USA. Majority of adults wear glasses (50\%), contact lenses $(14 \%)$ and very few undergo laser vision correction $(0.2 \%)$ each year.

The population of suitable candidates for LVC in years 2020-2021 is 150 million myopic and 50 million hyperopic patients.

If consideration is taken relating to age, severity of refraction, FDA approvals and affordability, of the 200 million potential candidates we estimate that the number decreases by $75 \%$ to 50 million as being the potential patient pool. This pool annually grows faster than patients being treated due to annual birth rates.

The two main factors causing patients to delay or not to have LVC over the last 25 years remains fear and cost or affordability. More recently professional misinformation from optometrists and adverse media articles have also caused patients to hesitate to have LVC. ${ }^{17-19}$

In 1995 following much anticipation and excitement, the Excimer laser was approved for refractive surgery by the FDA. Initially, the Summit Technology Inc., Apex excimer laser was approved on March 18, 1995 and on September 29, 1995 the VISX excimer system manufactured by AMO LLC was approved. ${ }^{20}$

The expectations by ophthalmologists, optometrists, the financial community, and laser manufacturing companies in the 1990's was that there were 'millions of patients' waiting to be treated with high expectation of a pent-up demand. ${ }^{21}$
Within three years of FDA approval over 65 Companies were registered in the USA to provide the LVC procedure in newly established free-standing centers in the USA. These Companies ranged from solo physician practices purchasing or leasing the equipment, to facilities offering open access similar to ambulatory surgery centers. Capital was raised both privately and publicly with estimated projections of billions of dollars in revenue annually.

Unfortunately, the projections never reached these optimistic projections. There were multiple reasons for these estimations being so wrong including patients fear of lasers being used on their eyes, to the cost of the procedure which was up to $\$ 3000$ per eye.

Furthermore, many ophthalmologists were reluctant to operate on a "normal" cornea with refractive errors. The lack of referrals from optometrists wanting to maintain their patients for annual eye examinations and continuing to sell glasses and contact lenses also played a part.

The FDA approvals progressed through multiple stages from photorefractive keratectomy (PRK) on a single eye with minimal astigmatism correction, to bilateral PRK and finally the less painful procedure of bilateral laser-assisted in situ keratomileusis (LASIK) for myopia and hyperopia including treating various forms of astigmatism. ${ }^{1-13}$ 
A total of 72 FDA labelling approvals have occurred for the laser manufacturers AMO, Carl Zeiss, VISX, LaserSight, Nidek, and Bausch and Lomb since 1995. ${ }^{22-24}$

Improvements in flap creation occurred as well with replacement of the mechanical microkeratome and its inherent flap risks to use of femtosecond laser for a "bladeless" or laser/laser refractive surgery. ${ }^{11-13}$

LASEK or Laser-Assisted Sub-Epithelial Keratectomy has similar disadvantages as PRK but probably less pain and more rapid healing but has obtained minimal penetration. Epi-LASIK is also infrequently performed. ${ }^{25,26}$

Newer developments have led to wavefront-guided and wavefront-optimized treatments that have minimized induction of higher order aberrations after refractive surgery. ${ }^{27-31}$

Topography guided ablations have provided the ability to treat irregular corneal topographic patterns and some studies have shown they may achieve even better uncorrected vision with normal topographic patterns. ${ }^{28}$

Other procedures began developing such as small incision lenticule extraction (SMILE) and phakic intraocular procedures with lens implanted either in front or behind the iris (IOLS). ${ }^{32-37}$

\section{Ophthalmologists and LVC}

There are over 19,000 licensed and practicing ophthalmologists both Medical Doctors (MD) and Doctors of Osteopathy (DO) in the USA. Over the last 25 years at least 6000 or a third have undergone some form of LVC training either in residency, fellowship or post-graduate courses organized by the manufactures and professional societies.

By 2020 nearly 4000 ophthalmologists were reported being refractive surgeons giving a ratio of one surgeon per 90,000 population. $^{14}$

Further findings show that 700 ophthalmologists perform nearly $80 \%$ of the LVC procedures. The majority perform approximately 2000 to 2500 procedures per annum with only approximately 100 to 200 surgeons focusing their practice exclusively on LVC.

During the financial crises, many ophthalmologists stopped performing LVC and began focusing on building a cataract or general ophthalmology practice.

As with all surgical procedures, there is a learning curve and results would indicate more experienced surgeons focusing exclusively on high volume LVC practices obtain best outcomes with the least number of unhappy patients and less potential or actual litigation.

\section{Centers Performing LVC}

The majority of LVC are performed in a fixed site facility of which there are over 1000 . These include approximately $65 \%$ being Surgeon-owned facilities, Corporate owned in $25 \%$ and less than $10 \%$ are hospital or military LVC treating centers. ${ }^{14,38}$

Currently there are no publicly traded companies performing LVC. From the initial Corporate companies started in the 1990s only several remain including LCA-Vision, Inc. The latter investors in 2020 acquired the Laser Vision Institute and TLC Vision centers from the Vision Group Holdings (VGH) bankruptcy, NuVision is predominately in California and the mobile laser company Sight Path offers a mobile "roll on, roll off" service for both LVC and cataracts.

The J\&J Visx and Alcon Wavelight account for over $90 \%$ of the installed base of over 1200 excimer lasers in the USA. ${ }^{14}$

Other companies manufacturing LVC lasers include Bausch \& Lomb, Nidek, Carl Zeiss, Schwind, LaserSight and Summit Autonomous Laser, bought by Alcon which was subsequently withdrawn from the market.

\section{Procedures (LASIK) Performed}

We estimate a total of 20 to 25 million laser vision correction procedures or 10 to 15 million patients were treated in the past 25 years.

Figure 3 is the graphic representation of annual LVC treatments performed over the last 25 years adapted from various sources. ${ }^{14,15}$ (See Figure 3)

LASIK will be the procedure of choice for many years to come and accounts for $80 \%$ to $85 \%$ of the procedures, PRK for $10-15 \%$ with the newer procedures such as SMILE, corneal inlay and other intraocular and phakic procedures are less than $5 \%$.

To the consumer "LASIK" is the generic name for all types of LVC surgeries.

From 1995 LVC procedures increased to 1.4 million procedures by 2000 where it maintained this level for several years and then declined related mainly to the economy which it has closely tracked. In the last 10 years procedural volume has been relatively flat ranging from 600,000 to 800,000 treatments per annum.

Nearly $45 \%(340,000)$ of procedures are performed by independent surgeons in their own offices or in freestanding surgery centers.

Corporate companies with less centers perform a similar $45 \%(345,000)$ procedures in their facilities. 
ESTIMATED LASER VISION CORRECTION (LASIK) PROCEDURES IN USA 1996 TO 2020

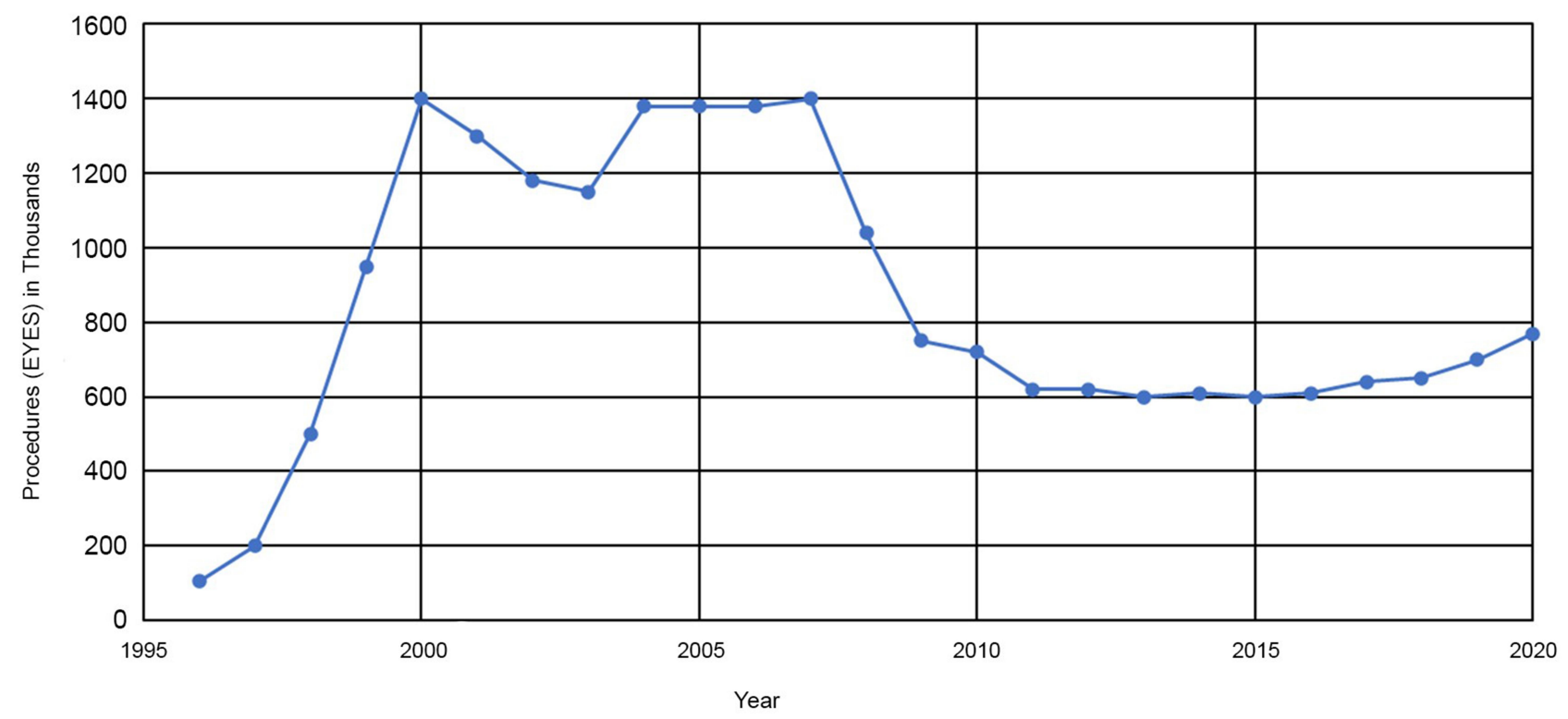

Figure 3 Estimated laser vision correction (LASIK) procedures in USA 1996-2020. This figure is composed of multiple sources including personal experience and the publications of both private and public companies of how many laser vison correction procedures are performed each year in the USA since FDA approval.

The military including and other hospital-based institutions account for under $10 \%(60,000)$ of the procedures. ${ }^{38}$

Covid-19 and the elective surgical "shutdown" including LVC caused a dramatic fall off in procedures in the $1^{\text {st }}$ and $2^{\text {nd }}$ quarters of 2020 but there has been a rebound at the end of $2^{\text {nd }}$ quarter, strong in 3 rd quarter and in the 4 th quarter in certain geographical areas declined due to "lockdowns" and increased fear of Covid-19 patients were reluctant to have elective surgery. This indicates that procedural volume for 2020 year will be less than 2019 .

\section{Pricing of LVC}

LVC is an elective surgical procedure and is rarely covered by insurance and for the majority of patients it is a self-pay or private pay procedure. Federal Savings Account (FSA) and Medical Savings Accounts (MSA) can be used for payment.

The recommended fees and final charge to a patient varies tremendously by geographical market, physician experience, name recognition, the refractive prescription, type of excimer laser used such as traditional, custom wavefront or wavefront guided, if punctal plugs were inserted and if the flap is created by mechanical blade or using a laser method.

Prices advertised to the consumer varies on various websites and the price ultimately paid by the patient, the Average Selling Price (ASP), maybe higher or lower depending on the various factors listed above.
Some facilities charge a fixed fee to include the preoperative examination, surgical procedure including drugs and disposables and postoperative visits which can vary from one to three visits or can be part of a "lifetime" plan. Enhancements which have declined over the years, may also be performed without cost for several years.

Discounts are often offered to entice patients to schedule visits for preoperative evaluation and for subsequent treatment.

Payments are made using cash (rare), credit cards (often), checks and especially by signing up for financing offered by commercial banks and financial institutions such as CareCredit.

The websites of the various corporate providers such as Laser Vision Institute (LVI), TLC Vision, LasikPlus and NVision offer prices varying from $\$ 1000$ to $\$ 4000$ per eye with promotions offering discounts either as a percentage or a reduction of a fixed dollar amount with an average ASP just under $\$ 2000$ per eye. Private practitioners charge an additional $\$ 500$ to $\$ 1000$ more per eye depending on experience and geographical locations The MarketScope 2020 reports an average price of $\$ 2632.00$ per eye in USA. ${ }^{14,15}$

Price is no indicator of quality or outcomes. Many corporate providers and high-volume surgeons have obtained a large amount of clinical experience. Some low-cost private providers may use older technologies with less preoperative evaluations and shorter postoperative follow-ups. 


\section{Income for Ophthalmologists from LVC}

The cumulative revenue for ophthalmologists performing LVC is less than $5 \%$ compared to nearly $30 \%$ from cataract surgery due to the larger number of annual cataract procedures.

Surgeons either stop performing LVC altogether and change to other procedures eg, cataracts if income decreases or perform both LVC and cataract surgeries, or exclusively perform LVC. The LVC surgery is performed either in their own private practice office(s) or by providing services to Corporate practices on a part-time or full-time basis.

Table 1 shows an estimated financial model of an LVC Center. The variables influencing profitability are the average selling price, the number of treatments performed, costs associated and efficiencies in patient conversion. The Table also illustrates the dramatic effect of doubling the surgical volume from 42 to 83 eyes per month which causes a seven times increase in gross profit.

Similarly, an increase in price by $\$ 400$ per eye has 2 to 3 times increase in gross profit. (See Table 1)

As surgeons become more established the word of mouth referral increases and the marketing costs can begin to decline.

The LVC Centers have great surgical capacity advantages. Fixed costs can stay the same with changes in volume and only the variable cost increases or decreases proportionately with volume changes.

Experiences and skilled surgeons performing LVC for over 20 years are reporting cumulative treatment volumes of 50,000 to 125,000 .

The surgical procedure is relatively fast, and patients can be "in and out" following an LVC treatment in less than two hours. Surgeons should not be pushed to go to fast and make mistakes.

Experienced surgeons treat up to four patients with bilateral LASIK in an hour and if staff is efficient, the centers can perform 60 to 80 treatments in a day. Certain surgeons, require a 30-minute period for each surgery and will not perform more than 10 to 20 treatments in a day depending on surgical experience and use of either the quicker microkeratome or slightly slower laser for creation of the flap.

\section{Outcomes and Patient Satisfaction After LVC}

LVC is an elective self-pay procedure with increased expectations from the patient regarding outcomes. Minimal requirements for LVC is freedom from glasses and contacts but more realistically is the desire for the equivalent or better vision often referred as 20/Happy. ${ }^{39}$ Patients expect a "red carpet or five star" professional experience and near perfect vision outcomes without pain or complications and a rapid recovery.

Multiple studies report outcomes from the initial FDA studies to large randomized and meta-analysis studies that show $99.5 \%$ of patients achieve $20 / 40$ vision and $90 \%$ to $95 \%$ achieve $20 / 20$ or better vision. The earlier complications of ghosting, halos, glare, difficulty with night vision do not occur. In $40 \%$ of contact lens wearers, dry eyes is reported which improves with LVC and intensive eyedrop regime. ${ }^{39-49}$

Ectasia is now treatable and preventable with corneal cross-linking and strict preoperative screening for subclinical keratoconus with topography and tomography. Neuropathic pain post-treatment is very rare. ${ }^{50-57}$

Table I Impact of Volume and Average Selling Price on Gross Profits

\begin{tabular}{|l|l|l|l|l|}
\hline Average Selling Price (ASP) & $\$ 1850$ & $\$ 1850$ & $\$ 2250$ & $\$ 2250$ \\
\hline Procedures per annum & 500 & 1000 & 500 & 1000 \\
\hline Revenue & $\$ 925,000$ & $\$ 1,850,000$ & $\$ 1,125,000$ & $\$ 2,250,000$ \\
\hline Variable Costs (\$350/eye) & $\$ 175,000$ & $\$ 350,000$ & $\$ 175,000$ & $\$ 350,000$ \\
\hline Contribution Margin & $\$ 750,000$ & $\$ 1,500,000$ & $\$ 950,000$ & $\$ 1,900,000$ \\
\hline Fixed Costs & $\$ 500,000$ & $\$ 500,000$ & $\$ 500,000$ & $\$ 500,000$ \\
\hline Marketing Costs (\$300/eye) & 150,000 & 300,000 & 150,000 & 300,000 \\
\hline Gross Profit & $\$ 100,000$ & $\$ 700,000$ & $\$ 300,000$ & $\$ 1,100,000$ \\
\hline
\end{tabular}

Notes: This table shows the two possible selling prices per eye of laser vision correction (LVC). By deducting the variable and fixed costs, a LVC center can have an annual gross profit of $\$ 100,000$ to over a $\$ 1$ million. The two major variables are the average selling price and the annual surgical volume. Fixed costs do not change until there is a much larger volume of cases. Variable costs include licensing fee, disposables, drops, blades. Fixed costs include rent, staff, depreciation (I,000 eyes per annum). 
Postoperative instructions for LASIK have become more simplified with patients returning to most activities within hours of surgery and by using a "common sense" approach.

Litigation is the worst outcome of LVC. Fortunately, LVC is one of the safest surgical procedures and many practices incorporate proactive methods to prevent litigation. A 20/unhappy patient is a dissatisfied customer even if the uncorrected vision is $20 / 20$ or even $20 / 15$.

The issue of needing reading glasses for presbyopia remains an issue for patients due to the advertising message of "freedom from glasses and contacts." Similarly, monovision or blended vision for older patients requires education and pretreatment trials with only $50 \%$ of patients being candidates for surgery.

Malpractice claims peaked in LVC in year 2000 and with a steep decline since then. Ophthalmic Mutual Insurance Company (OMIC), the insurer of nearly a third of ophthalmologists stated that the majority of their claims are settled are for less than $\$ 100,000$. The PRK claims occur less frequently but have greater payments. ${ }^{58}$

Over the past decade since the great recession (20072009) there has been a concerted effort by optometrists to misinform patients not to get laser vision correction by telling them astigmatism could not be treated, presbyopia could not be helped and other reasons given to misinform patients. Recently, half the phone calls to a Californian LVC office were asking if astigmatism could be treated. Furthermore, negative news stories brought on by the campaign by Morris Waxler $\mathrm{PhD}$, the former FDA advisor from 1996 to 2001 initially involved in the approval of Lasik was now discrediting LASIK in the press resulting in a negative impact on procedure numbers. Misinformation programs are also one of the reasons for the lack of increase in laser vision correction procedures.

To overcome negative press an assessment of postrefractive symptoms was carried out by the FDA in collaboration with the National Eye Institute (NEI). A questionnaire was developed for patients following LASIK at the US Naval Medical Center in San Diego with 262 participants and completed in 2014 was called PROWL-1 an acronym for the Patient Reported Outcomes with Lasik and an additional study in 312 civilian postoperative patients was called PROWL-2.

In each of the PROWL studies, less than $1 \%$ of patients experienced difficulty performing their usual activities following LASIK surgery due to any one symptom and more than $95 \%$ were satisfied with their vision. ${ }^{59-63}$
As so few patients experienced debilitating symptoms, the FDA decided with its limited resources not to conduct a larger clinical study to estimate prevalence of complications more accurately or find useful predictors in post-LASIK patients.

Patients besides assessing the risk versus benefits of LVC, should also include expected cost savings. The indirect and direct expenditure is equal to 8 to 10 years of purchasing glasses, contact lenses, solutions and eyecare visits. ${ }^{64}$

Consideration of time to insert lenses and benefits of "lens free" occupations for firefighters, police, healthcare workers, safety for mothers and athletic benefits for swimmers, runner and bikers.

\section{Consolidation and Buyouts in Ophthalmology}

Private equity has been purchasing many ophthalmic private practices often at premium prices. In the future, these private practices will need to increase and find alternative sources of revenue. One area is enlarge the refractive practices by advertising and increasing the optometric comanagement referrals. Mergers will continue and new companies will enter the refractive market as the myopic epidemic continues.

At end of 2019, there were 29 private equity firms actively investing in ophthalmology. A total of 228 ophthalmic and optometric practices were purchased between 2012 and 2019 which included 1466 clinical locations. ${ }^{65,66}$

\section{Covid-I 9 Pandemic and Telemedicine in LVC} With forced closures for elective LVC centers due to Covid-19 pandemic from late March 2020 to slow reopening in early June 2020, the practice of LVC changed. ${ }^{67}$

Teleophthalmology consultation during center closure went from minimal to nearly $80 \%$ with potential patients scheduling surgery without an examination.

Patients appeared knowledgeable of their vision prescriptions and had minimal questions besides asking about potential dates for surgery, recovery time and if any experience of pain. Cost appeared less of a problem with money being available to pay for the procedure.

Factors motivating patients were glasses fogging up with wearing masks, known as "glass fog", increased risk of wearing contact lenses due to facial hygiene with less touching and patients physical facial appearance on internet communication such as Zoom and Microsoft Teams. ${ }^{68}$ 
As a result, similar to cataracts there is a pent-up demand for LVC.

Following reopening of surgery centers in areas no longer under lockdown, there has been an increase in LVC and other procedures including facial aesthetic surgeries. ${ }^{69}$

Plotting the back log of LVC surgery post-covid using the Monte Carlo stimulation applied to elective cataract surgery study, we estimate an optimistic additional 300,000 LASIK surgeries in years 2021 to $2022 .{ }^{16}$

LVC can be performed safely with Covid-19 precautions including requesting all patients to wear masks, restrict distances in waiting rooms, asking family and friends to wait in cars outside, extensive cleaning procedure rooms between each patient and using transparent physical barriers where appropriate. ${ }^{67}$

Despite all these new procedures, treatment efficiencies are being maintained after the initial learning curve. Preoperative and postoperative visits are by telemedicine if possible, with minimal physical contact between LVC staff and patients.

\section{Conclusion}

Laser vision correction (LVC) has now reached its 25th anniversary since FDA approval in the USA. We estimate 20 to 25 million eyes have been treated giving a very low $0.2 \%$ penetration of treatments per annum for the refractive conditions of myopia, hyperopia with astigmatism.

The compounded annual growth rate for LVC is under $2 \%$ which is too low for a procedure which is safe, cost effective and reliable.

Word of mouth from satisfied patients, comanagement, internet patient reviews and consumer marketing are the main drivers for LVC treatments.

Cost and fear are still the major factors delaying treatments. Fear has become less with the Covid-19 epidemic due to masks fogging up glasses.

More telehealth consultations are needed with less office visits pre- and postoperatively. Reduction in pricing to make LVC more affordable will help considerably.

Surgical outcome results have improved dramatically over the 25 years especially in high volume facilities where processes have become standardized and best practices instituted reducing errors by staff and ophthalmologist.

To increase the current low penetration of refractive surgery, word of mouth referrals and social media reviews from past patients' needs to spread the message of the availability of a relatively painless procedure at an affordable price being available to correct an incapacitating refractive error. Treated patients will not need to wear their glasses or contact lenses for their financially and professionally productive years until they become presbyopic with advancing years.

\section{Acknowledgments}

I would like to thank Lisa Blaker of Joffe Foundation, Cincinnati, Ohio, USA, for medical writing assistance and preparation of the manuscript and Lewis Groden, MD, Dean Ellis, MD and Lou Probst, MD Medical Directors of LasikPlus Vision Centers, and LCA-Vision, Inc., Cincinnati, Ohio for clarification of LVC treatments.

\section{Disclosure}

The author reports no conflict of interest in this work.

\section{References}

1. Partal AE, Manche EE. CustomVue laser in situ keratomileusis for myopia and myopic astigmatism using the Visx S4 excimer laser: efficacy, predictability, and safety. J Cat Refract Surg. 2006;32 (3):475-479. doi:10.1016/j.jcrs.2005.12.128

2. Sekundo W, Bonicke K, Mattausch P, Wiegand W. Six year follow-up of laser in situ keratomileusis for moderate and extreme myopia using a first-generation excimer laser and microkeratome. $J$ Cat Refract Surg. 2003;29:1152-1158. doi:10.1016/S0886-3350(03)00062-2

3. Ibrahim O. Laser in situ keratomileusis for hyperopia and hyperopic astigmatism. J Cat Refract Surg. 1998;14:S179-S182.

4. Schallhorn SCS, Farjo AA, Huang D, et al. Wavefront-Guided LASIK for the correction of primary myopia and astigmatism. Am Acad Ophthalmol. 2008;115:1249-1261.

5. Lim T, Yang S, Kim M, Tchah H. Comparison of the IntraLase femtosecond laser and mechanical microkeratome for laser in situ keratomileusis. Ameri J Ophthalmol. 2006;141:833-839. doi:10.10 16/j.ajo.2005.12.032

6. Manche EE, Carr JD, Haw WW, Hersh PS. Excimer laser refractive surgery. West J Medi. 1988;169(1):30-38.

7. Salah T, Waring GO, El Maghraby A, Moadel K, Grimm SB. Excimer laser in situ keratomileusis under a corneal flap for myopia of 2 to 20 diopters. Amer J Ophthalmol. 1996;121(2):143-155. doi:10.1016/S0002-9394(14)70578-1

8. Probst LE, Machat JJ. Mathematics of laser in situ keratomileusis for high myopia. J Cat Refract Surg. 1998;24(2):190-195. doi:10.1016/ S0886-3350(98)80199-5

9. McDonald MB, Kaufman HE, Frantz JM, Shofner S, Salmeron B, Klyce SD. Case Report: excimer laser ablation in a human eye. Arch Ophthal. 1989;107(5):641-642. doi:10.1001/archopht.1989.0107001 0659013

10. Sutton G, Lawless M, Hodge C. Laser in situ keratomileusis in 2012: a review. Clin Exp Optom. 2014;97(1):18-29. doi:10.1111/cxo.12075

11. Patel SV, Maguire LJ, McLaren JW, Hodge DO, Bourne WM. Femtosecond laser versus mechanical microkeratome for LASIK: a randomized controlled study. Ophthalmol. 2007;114(8):14 82-1490. doi:10.1016/j.ophtha.2006.10.057

12. Xia LK, Yu J, Chai GR, Wang D, Li Y. Comparison of the femtosecond laser and mechanical microkeratome for flap cutting in LASIK. Inter J Ophthalmol. 2015;8(4):784-790. 
13. Pajic B, Vastardis I, Pajic-Eggspuehler B, Gatzioufas Z, Hafezi F. Femtosecond laser versus mechanical microkeratome-assisted flap creation for LASIK: a prospective, randomized, paired-eye study. Clin Ophthalmol. 2014(8):1883-1889.

14. Jones C. Refractive Surgery Market Report. MarketScope. 2019; 2020:1-283.

15. Harmon D. US Refractive Quarterly Update. MarketScope. 2020;1-23.

16. Aggarwal S, Jain P, Jain A. Covid-19 and cataract surgery backlog in Medicare beneficiaries. J Cat Refract Surg. 2020;46(11):1530-1533. doi: $10.1097 /$ j.jcrs.0000000000000337

17. Pesudovs K, Garamendi E, Elliot DB. A quality of life comparison of people wearing spectacles or contact lenses or having undergone refractive surgery. J Refract Surg. 2006;22(1):19-27. doi:10.3928/ 1081-597X-20060101-07

18. Tran K, Ryce A Laser refractive surgery for vision correction: a review of clinical effectiveness and cost-effectiveness Available from: https://www.cadth.ca/sites/default/files/pdf/htis/2018/ RC0992\%20Laser\%20Refractive\%20Surgery\%20for\%20Vision\% 20Correction\%20Final.pdf. Canadian Agency for Drugs and Technologies in Health; Ottawa (ON). Accessed January 26, 2021.

19. McAlinden C. Corneal refractive surgery: past to present. Clin and Exper Optom. 2012;95(4):386-398. doi:10.1111/j.1444-0938.2012.00 761.x

20. FDA-Approved Lasers for PRK and Other Refractive Surgeries; 2021. Available from: https://www.fda.gov/medical-devices/LASIK/fdaapproved-lasers-prk-and-other-refractive-surgeries. Accessed January $28,2021$.

21. Wilksinson JM, Cozine EW, Kahn AR. Refractive eye surgery: helping patients make informed decisions about LASIK. Amer Fam Phy. 2017;95(10):637-644.

22. Payvar S, Hashemi H. Laser in situ keratomileusis for myopic astigmatism with the Nidek EC-5000 laser. J Refract Surg. 2002;18 (3):225-233.

23. Reviglio VE, Bossana EL, Luna JD, Muiño JC, Juarez CP. Laser in situ keratomileusis for myopia and hyperopia using the Lasersight 200 laser in 300 consecutive eyes. J Refract Surg. 2000;16(6): 716-723.

24. Khoramnia R, Salgado JP, Wuellner C, Donitzky C, Lohmann CP, Winkler von Mohrenfels C. Safety, efficacy, predictability and stability of laser in situ keratomileusis (LASIK) with a 1000-Hz scanning spot excimer laser. Acta Ophthalmol. 2012;90(6):508-513. doi:10.11 11/j.1755-3768.2010.02052.x

25. Lee JY, Youm DJ, Choi CY. Conventional Epi-LASIK and lamellar epithelial debridement in myopic patients with dermatologic keloids. Kor Jnl of Ophthal. 2011;25(3):206-209. doi:10.3341/kjo.2011.25. 3.206

26. Teus MA, de Benito-llopis L, Garcia-González M. Comparison of visual results between laser-assisted subepithelial keratectomy and epipolis laser in situ keratomileusis to correct myopia and myopic astigmatism. Amer J Ophthalmol. 2008;146(3):357-362. doi:10.10 16/j.ajo.2008.05.022

27. Moshirfar M, Shah TJ, Skanchy DF, Linn SH, Kang P, Durrie DS. Comparison and analysis of FDA reported visual outcomes of the three latest platforms for LASIK: wavefront guided Visx iDesign, topography guided WaveLight Allegro Contoura, and topography guided Nidek EC-5000 CATz. Clin Ophthal. 2017;11:135-147. doi:10.2147/OPTH.S115270

28. El Awady HE, Ghanem AA, Saleh SM. Wavefront-optimized ablation versus topography-guided customized ablation in myopic LASIK: comparative study of higher order aberrations. Ophthalmic Surgery. 2011;42(4):314-320. doi:10.3928/15428877-20110421-01

29. Shehadeh MM, Akkawi MT, Aghbar AA, et al. Outcomes of Wavefront-Optimized Laser-Assisted In-Situ Keratomileusis and Photorefractive Keratectomy for correction of Myopia and Myopic Astigmatism over One Year Follow-Up. Open Ophthalmol J. 2018;12 (1):256-263. doi:10.2174/1874364101812010256
30. Artini W, Riyanto B, Hutauruk JA, D. Gondhowiardjo T, Kekalih A. Predictive factors for successful high myopia treatment using high-frequency laser-in-situ keratomileusis. Open Ophthal Jnl. 2018;12(1):214-225. doi:10.2174/1874364101812010214

31. Motwani M, Pei R. Treatment of moderate-to-high hyperopia with the WaveLight Allegretto 400 and EX500 excimer laser systems. Clin Ophthal. 2017;11:999-1007. doi:10.2147/OPTH.S136061

32. Xia LK, Maj LHN, Shi C, Huang Q. Three-year results of small incision lenticule extraction and wavefront-guided femtosecond laser-assisted laser in situ keratomileusis for correction of high myopia and myopic astigmatism. Inter Ophthal. 2018;11(3):470-477.

33. Shah R. History and Results; Indications and Contraindications of SMILE Compared With LASIK. The Asia-Pacific J Ophthal. 2019;8 (5):371-376. doi:10.1097/01.APO.0000580132.98159.fa

34. Chiam NPY, Mehta JS. Comparing patient-reported outcomes of laser in situ keratomileusis and small-incision lenticule extraction: a review. Asia Pacific J Ophthal. 2019;8(5):377-384. doi:10.1097/APO.00 00000000000258

35. Kanellopoulos AJ. Topography-Guided LASIK Versus Small Incision Lenticule Extraction (SMILE) for Myopia and Myopic Astigmatism: a Randomized, Prospective, Contralateral Eye Study. J Refract Surg. 2017;33(5):306-312. doi:10.3928/1081597X-20170221-01

36. Kymionis GD, Grentzelos MA, Kalyvianaki MI, et al. Fifteen-year follow-up after anterior changer phakic intraocular lens implantation in one and LASIK in the fellow eye. Semin Ophthalmol. 2009;24 (6):231-233. doi:10.3109/08820530903388751

37. Tsiklis NS, Kymionis GD, Kap CL, Naoumidi T, Pallikaris AI. Nineyear follow-up of a posterior chamber phakic IOL in one eye and LASIK in the fellow eye of the same patient. $J$ Refract $S .2007 ; 23$ (9):935-937. doi:10.3928/1081-597X-20071101-12

38. Hammond MD, Madigan JWP, Bower KS. Refractive surgery in the United States Army, 2000-2003. Ophthal. 2005;112:184-190. doi:10.1016/j.ophtha.2004.08.014

39. Solomon KD, Fernandez LE, Sandoval HP, et al. LASIK World Literature Review Quality of life and patient satisfaction. Ophthal. 2009;116(4):691-701. doi:10.1016/j.ophtha.2008.12.037

40. Toda I. Dry Eye After LASIK. Invest Ophthal Vis Scie. 2018;59 (14):109-115. doi:10.1167/iovs.17-23538

41. Jun I, Jung JW, Choi YJ, Kim TI, Seo KY, Kim EK. Long-term clinical outcomes of phototherapeutic keratectomy in corneas with granular corneal dystrophy type 2 exacerbated after LASIK. $J$ Refract Surg. 2018;34(20):132-139. doi:10.3928/1081597X20171220-01

42. Alió JL, Ortiz D, Muftuoglu O, Garcia MJ. Ten years after photorefractive keratectomy (PRK) and laser in situ keratomileusis (LASIK) for moderate to high myopia (control-matched study). Brit Ophthal. 2009;93(10):1313-1318. doi:10.1136/bjo.2007.1 31748

43. Xie W. Recent advances in laser in situ keratomileusis-associated dry eye. Clinic Exper Optom. 2016;99(2):107-112. doi:10.1111/cxo.12361

44. Toda I, Asano-Kato N, Tsubota K. Dry eye after laser in situ keratomileusis. Am J Ophthalmol. 2001;132(1):1-7. doi:10.1016/ S0002-9394(01)00959-X

45. De Paiva CS, Chen Z, Koch DD, et al. The incidence and risk factors for developing dry eye after myopic LASIK. Am J Ophthalmol. 2006;141(3):438-445. doi:10.1016/j.ajo.2005.10.006

46. Yu EY, Leung A, Rao S, Lam DS. Effect of laser in situ keratomileusis on tear stability. Ophthal. 2000;107(12):2131-2135. doi:10. 1016/S0161-6420(00)00388-2

47. Ting DSJ, Srinivasan S, Danjoux JP. Epithelial ingrowth following laser in situ keratomileusis (LASIK): prevalence, risk factors, management and visual outcomes. BMJ Open Ophthalmol. 2018;3(1): e000133. doi:10.1136/bmjophth-2017-000133

48. Smith RJ, Maloney RK. Diffuse lamellar keratitis. A new syndrome in lamellar refractive surgery. Ophthalmol. 1998;105(9):1721-1726. doi:10.1016/S0161-6420(98)99044-3 
49. AlQahtani BS, Alshahrani S, Khayyat WW, et al. Outcomes of corneal topography among progressive keratoconus Patients 12 months following Corneal Collagen Cross-Linking. Dove Press. 2021;2021(15):49-55.

50. Giri P, Aza DT. Risk profiles of ectasia after keratorefractive surgery. Curr Opin Ophthalmol. 2017;28(4):337-342. doi:10.1097/ICU.000 0000000000383

51. Hafezi F, Kanellopoulos J, Wiltfang R, Seiler T. Corneal collagen crosslinking with riboflavin and ultraviolet a to treat induced keratectasia after laser in situ keratomileusis. J Cat Refract Surg. 2007;33 (12):3025. doi:10.1016/j.jcrs.2007.07.028

52. Randleman JB, Woodward M, Lynn MJ, Stulting RD. Risk assessment for ectasia after corneal refractive surgery. Opthal. 2008;115 (1):37-50. doi:10.1016/j.ophtha.2007.03.073

53. Randleman JB, Trattler WB, Stulting RD. Validation of the Ectasia Risk Score System for preoperative laser in situ keratomileusis screening. Am J Ophthal. 2008;145(5):813-818. doi:10.1016/j.ajo.20 07.12 .033

54. Ong HS, Farook M, Tn BBC, Williams GP, Santhiago MR, Mehta JS. Corneal ectasia risk and percentage tissue altered in myopic patients presenting for refractive surgery. Clin Ophthal. 2019;13:2003-2015. doi: $10.2147 /$ OPTH.S215144

55. Pallikaris IG, Kymionis GD, Astyrakakis NI. Corneal ectasia induced by laser in situ keratomileusis. J Cat Refract Surg. 2001;27 (11):1796-1802. doi:10.1016/S0886-3350(01)01090-2

56. Mazzotta C, Sgheri A, Bagaglia A, Rechichi M, Di Maggio A. Customized corneal crosslinking for treatment of progressive keratoconus: clinical and OCT outcomes using a transepithelial approach with supplemental oxygen. $J$ Cat Refract Surg. 2020;46(12):15 82-1587. doi:10.1097/j.jcrs.0000000000000347

57. Wan Q, Wang D, Ye H, Tang J, Han Y. A review and meta-analysis of corneal cross-linking for post-laser vision correction ectasia. J Curr Ophthalmol. 2017;29:145-153. doi:10.1016/j.joco.2017.02.008

58. Ophthalmic Mutual Insurance Company (OMIC) Homepage/Website. Available from: https://www.omic.com. Accessed February 1, 2021.

59. Sugar A, Hood C, Mian S. Patient-reported outcomes following LASIK: quality of Life in the PROWL Studies. JAMA. 2017;317 (2):204-205. doi:10.1001/jama.2016.19323
60. Clayton JA, Eydelman M, Vitale S, et al. Web-based versus paper administration of common ophthalmic questionnaires: comparison of subscale scores. Ophthal. 2013;120(10):2141-2159. doi:10.1016/j. ophtha.2013.03.019

61. Tarver M, Hilmantel G, Eydelman M. FDA Efforts: patient Perspective on LASIK. Rev Cornea Contact Lenses. 2017;1-5.

62. Hays RD, Tarver ME, Spritzer KL, et al. Assessment of the Psychometric Properties of a Questionnaire Assessing Patient-Reported Outcomes With Laser In Situ Keratomileusis (PROWL). JAMA Ophthalmol. 2017;135(1):3-12. doi:10.1001/ jamaophthalmol.2016.4597

63. Eydelman MB, Tarver ME, Ferris III F. Listening to the patients - the Laser-Assisted In Situ Keratomileusis Quality of Life Collaboration Project. JAMA. 2017;135(2):83-84.

64. Berdeaux G, Alio J, Martinez J-M, Magaz S, Badia X. Socioeconomic aspects of laser in situ keratomileusis, spectacles, and contact lenses in mild to moderate myopia. J Cat Refract Surg. 2002;28:1914-1923. doi:10.1016/S0886-3350(02)01496-7

65. Chen EM, Cox JT, Begaj T, Armstrong GW, Khurana RN, Parikh R. Private equity in ophthalmology and optometry: analysis of acquisitions from 2012 through 2019 in the United States. Ophthal. 2020;127(4):445-455. doi:10.1016/j.ophtha.2020.01.007

66. Yetter EJ List of private equity firms investing in ophthalmology practices and surgery centers; 2020. Available from: https://www. physiciansfirst.com/post/list-of-private-equity-firms-investing-inophthalmology-practices-and-surgery-centers. Excerpt from published White Paper Physicians First. Accessed January 29, 2021.

67. Stodola E Patterns in LASIK cases since reopening practices. Available from: https://www.eyeworld.org/patterns-LASIK-casesreopening-practices. 2020. Accessed December 15, 2020.

68. Fadlallah A, Khattar G, Habre C, Khanafer D. LASIK procedures during COVID-19. J Cat Refract Surg. 2020;46(12):1682. doi:10.10 97/j.jcrs.0000000000000338

69. CBS New York. COVID Pandemic Prompts Uptick in LASIK Surgery Procedures. Available from: https://newyork.cbslocal.com/ 2020/10/27/covid-pandemic-prompts-uptick-in-LASIK-surgeryprocedures/. Accessed December 15, 2021.
Clinical Ophthalmology

\section{Publish your work in this journal}

Clinical Ophthalmology is an international, peer-reviewed journal covering all subspecialties within ophthalmology. Key topics include: Optometry; Visual science; Pharmacology and drug therapy in eye diseases; Basic Sciences; Primary and Secondary eye care; Patient Safety and Quality of Care Improvements. This journal is indexed on PubMed
Central and CAS, and is the official journal of The Society of Clinical Ophthalmology (SCO). The manuscript management system is completely online and includes a very quick and fair peer-review system, which is all easy to use. Visit http://www.dovepress.com/ testimonials.php to read real quotes from published authors. 